\title{
SEROREVELATION OF ANTIBODIES OF EQUINE HERPESVIRUS (EHV1/EHV4) IN SYRIA
}

(With One Table and Two Figures)

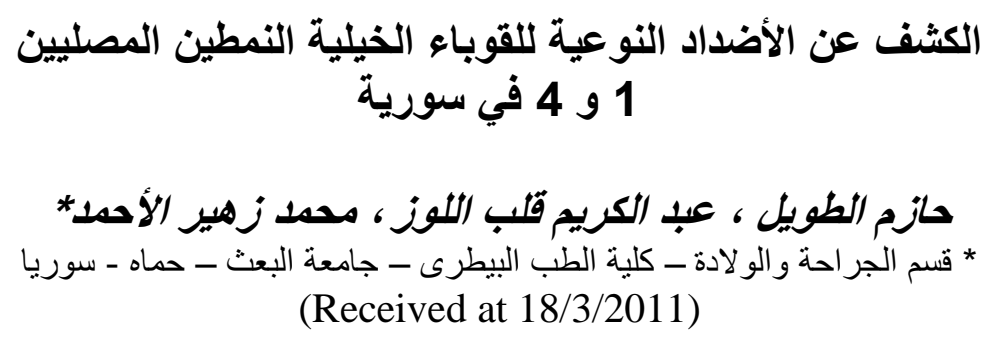

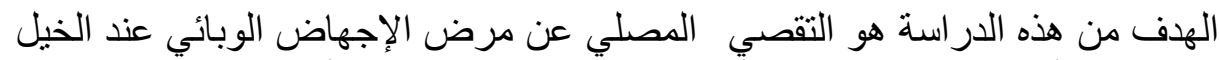

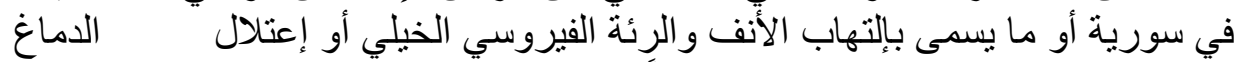

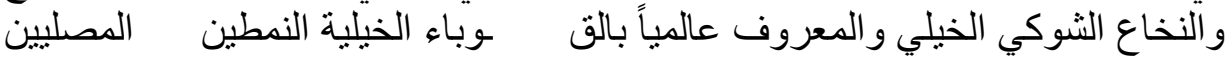
ت و EHV1)

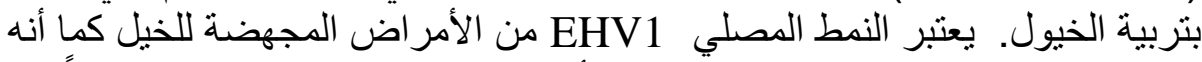
يسبب اضطر ابات تنفسية و عصبية في حين الني النية النمط

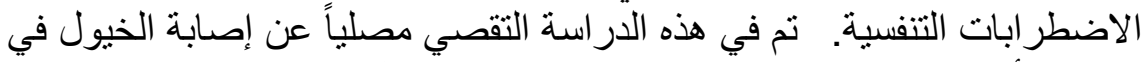

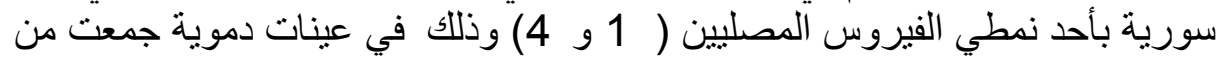

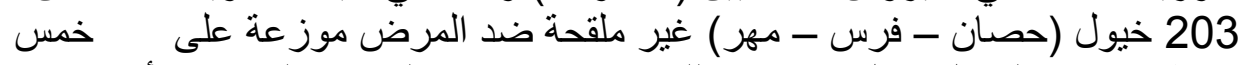

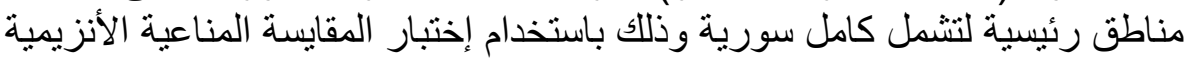

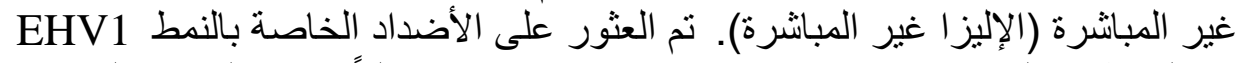

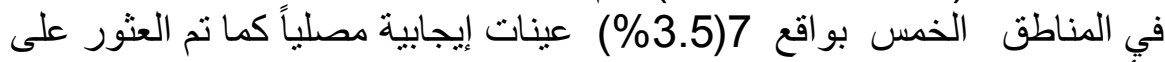
الأضداد الخاصة بالنمط EHV4 في المناطق الخمس بو اقع 193 196 (96\%) عينت إيجابية مصلياً. و هذه أول دراسة للتقصي عن هذا المرض في سوريا.

\section{SUMMARY}

The objective of this study is, serological investigation of Epizootic Equine Abortion (EEA) or Equine Rhinopneumonitis (ER) Equine Herpesvirus Myeloencephalopathy (EHM) that know worldwide Equid herpesvirus (EHV type 1 and 4) in Syria. Equid 
herpesvirus 1 and 4 are widespread in the domestic horses population worldwide. EHV1 is a major cause of abortion, respiratory and neurological disorders in horses. EHV4 is responsible of respiratory disease. In this study, Antibodies of EHV1 and 4 were investigated serologically in horses in Syria. A total of 203 unvaccinated horses in five regions in Syria were sampled and tested using indirect ELISA. EHV1-specific antibodies were found to be in fifth regions as 7(3.5\%). EHV4specific antibodies were found to be in fifth regions as 195(96\%). This is the first serological investigation for EHV1 and EHV4 in Syria.

Key words: Epizootic equine abortion, equine herpesvirus, serology, Syria.

\section{INTRODUCTION المقدمـة}

إن مرض التهاب الأنف والرئة المعدي أو مرض الإجهاض الوبائي الخيلي

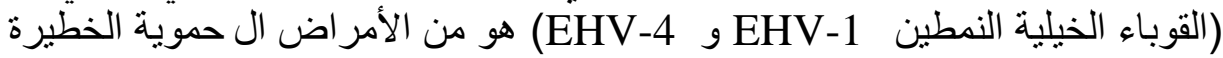
التي تصيب الخيول كما يعد هذا المرض العاب العامل الرئيسي لظهور

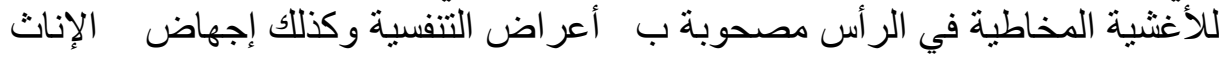

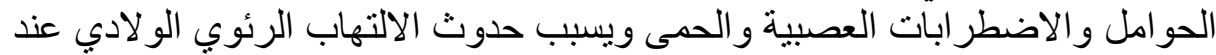

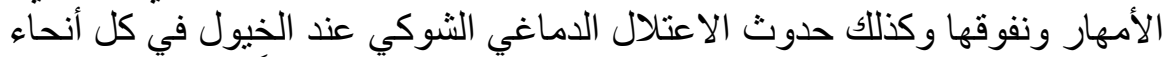

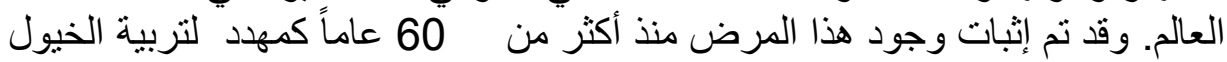
(O’Callaghan et al., 1983; Allen and Bryans, 1986 ; Bryans العالمية وندان and allen, 1988; Allen et al., 1999;

Crabb and Studdert, 1995)

حتى عام 1981 كان يعتقد أن النمطين المصليين للحمة يشكلان نمطاً مصلياً

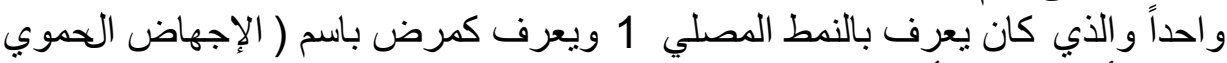

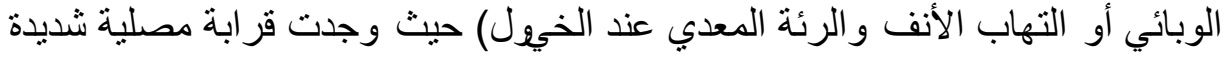

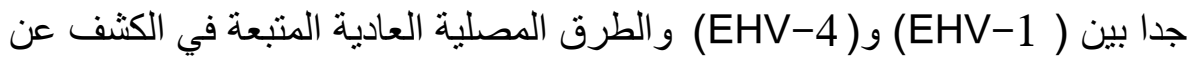

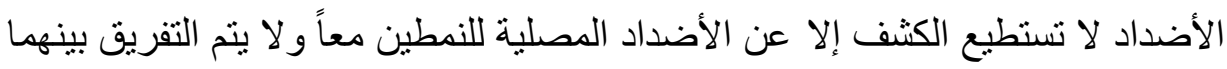

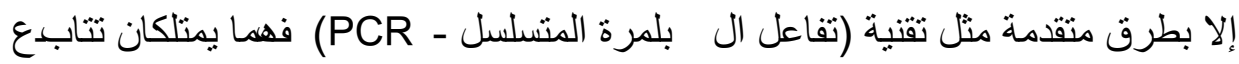

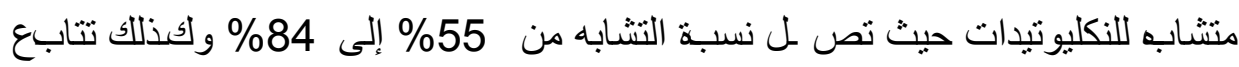


متشابه للأحم اض الأمينية يصل من 55\% إلى 96\%. ; Telford et al., 1992 ) (1998. لكن بينت نتيجة الفحوصات لتحديد البنية الداخلية النكليوزيدية للدنا أنهما

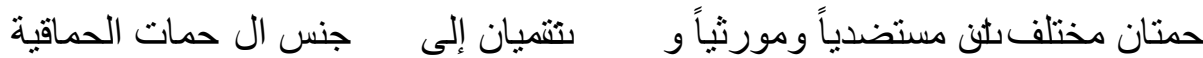
( التي تنتمي لتحت عائلة $\quad$ (Varicellovirus) (Studdert 1974; Sabine et al., 1981) (Alphaharpesvirina) بدورهـا تتتم -ي إلـى عائلة حمـات القوباء (Herpesviridae) .Wise, 2006)

ينتشر المرض في معظم دول العالم ويعد كمشكلة عالمية تهدد تربية الخيول

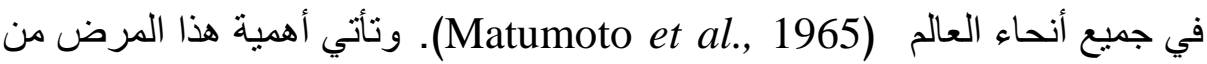

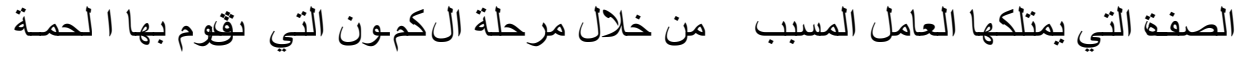

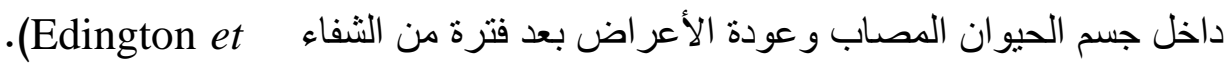
al., 1994) يصيب المرض الخيول بالدرجة الأولى، ثم تأتي الحمير و البغال بالدرجة

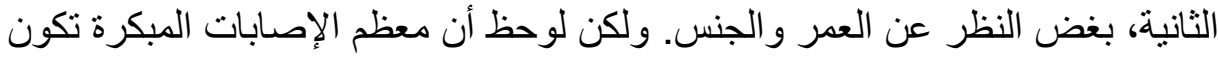
عند الخيول بعد إتمامها الثهر الثاني عثر من عمر ها ل (Edington et al., 1994). و هنالك در اسات تدل على انتش ـار إصابات تنفسية كثيرة قبل سن الفطام عند الأمهار

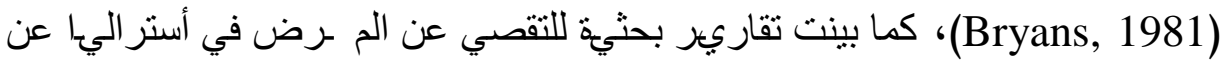

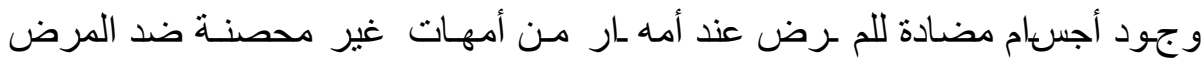
بعمر شهر واحد فقط (Gilkerson et al., 1997).

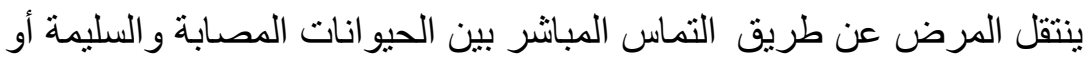

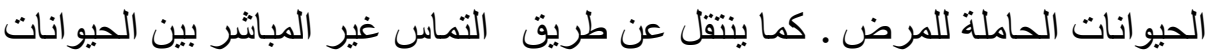

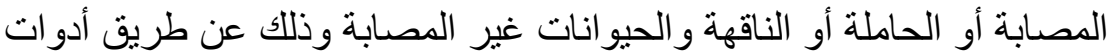

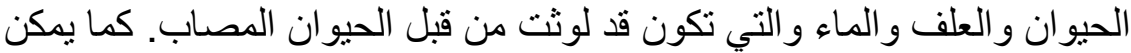

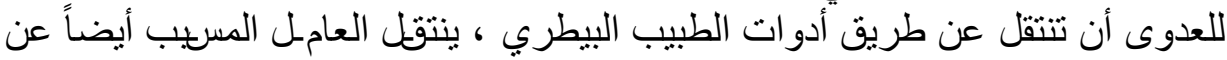

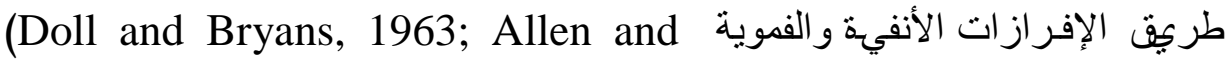

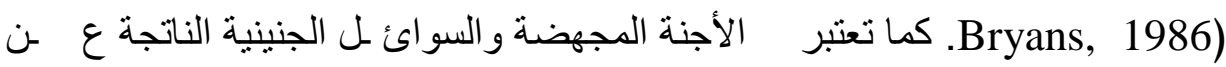

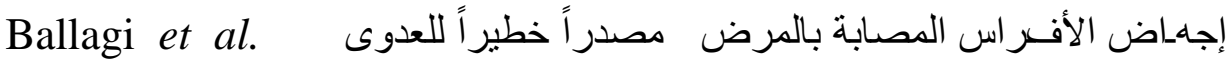




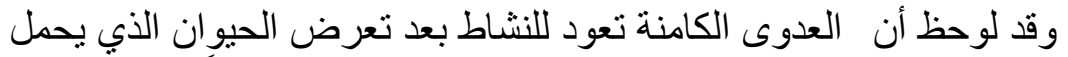

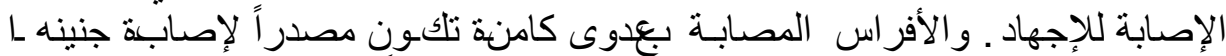

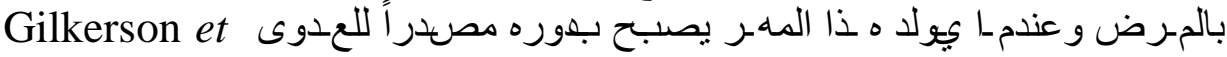

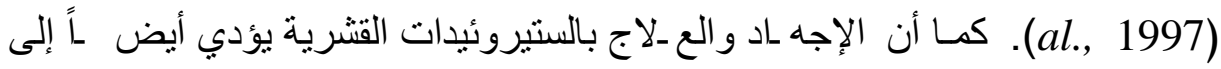

تنشيط الحمـة وعودة العدوى من جديد (Welch et al., 1992; Slater 2007).

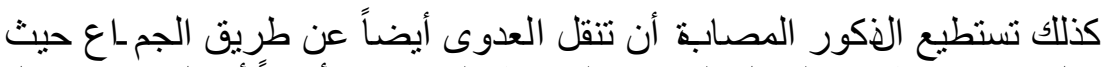

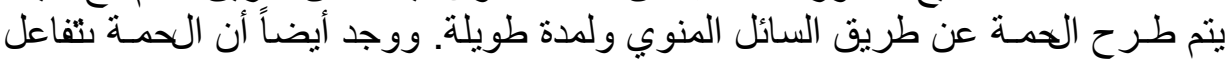

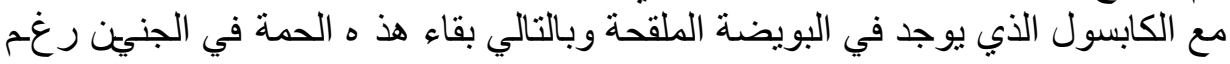

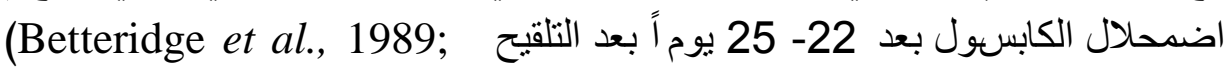

.Carvalho et al., 2000)

من أهم الأعر اض التي تظهر على الحيوان الحمى حيث تصل درجة الحرارة

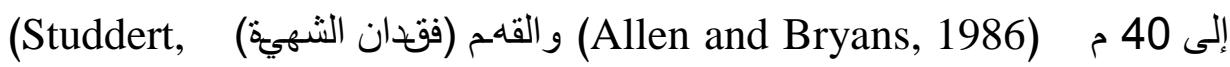

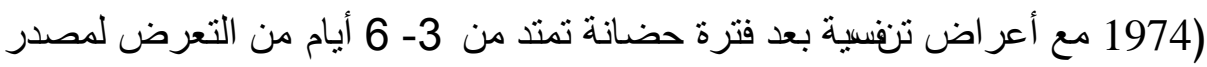

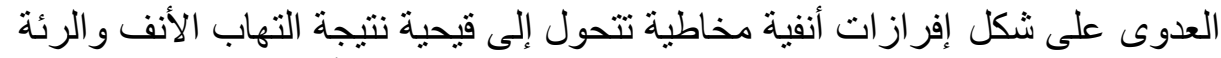

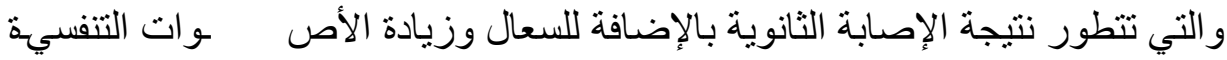
و الإفواز ات العينية (Bryans and Allen, 1989). تحدث الإصابة التنفسية بشكل الإنكل

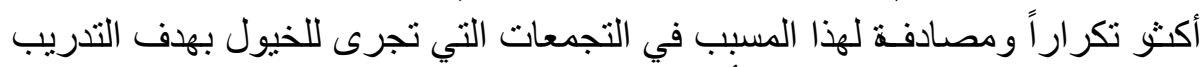
والسباقات ومنافسات الفروسية الأخرى

(OIE Terrestrial Manual 2008) بالنمط الفيروسي 4 عند الخيول بعمر فوق ( 2-3) سنة وتكون الأعر اض منتابهة مع الإبة الإنة الإصابة التنفسية بالنمط 1 (Edington et al., 1991). تحدث الإصابة التنفسية بالنمط ( EHV-1) في الخيول اليافعة تحت 2 سنة وفي الإناث الحوامل و الإناث الضعيفة والذكور كبيرة العمر والضعيفة (Allen et al., 2004) ـ إن الخطر التالي

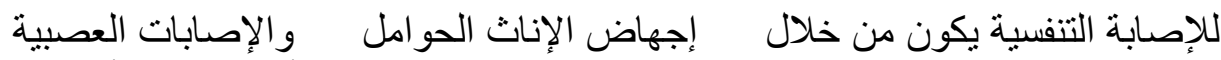

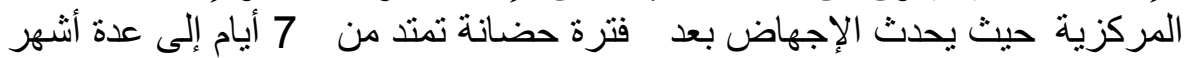

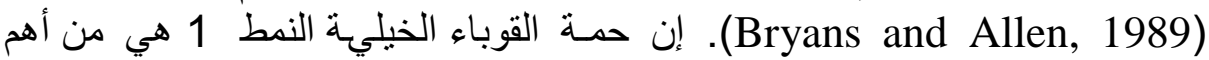

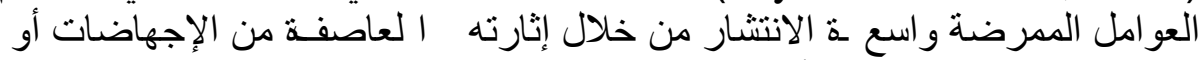

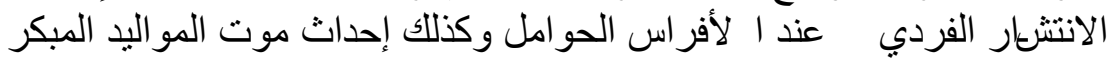

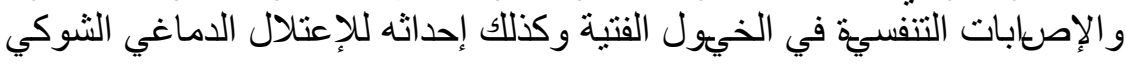
.(Van Maanen, 2002; Reed and Toribio 2004; Patel and Heldens, 2005) 
تجهض الأفراس الحوامل عادةً في الفترة بين 6 و 11 شهر اً من الحمل حتى

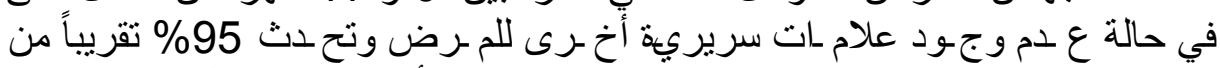

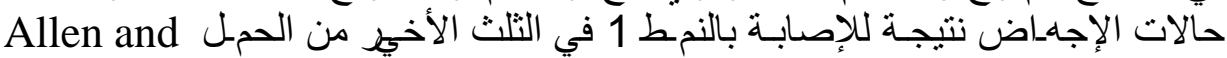

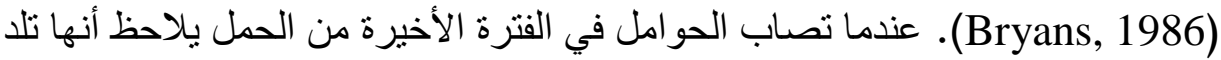

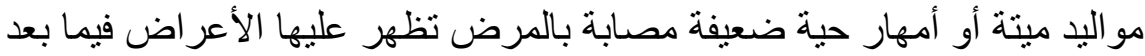
وتنفق خلال ثناثة أيام (Van Maanen et al., 2000).

يتم تتخيص المرض حقلياً عن طريق مشاهدة الأعر اض والصفية التشريحية

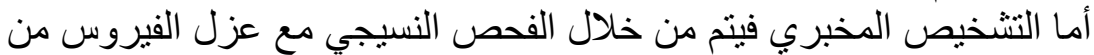
الأعضاء المتضررة (الكبد-الجنين المجهض-العقد البلغمية). يستخدم اختبار الـ

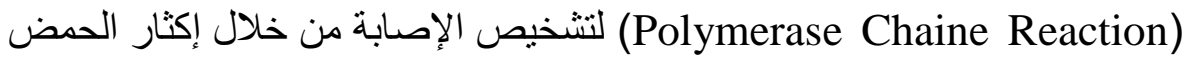
النووي الفيروسي للنمطين 4/1 في العينات السريرية النسيجية حتى العينات المحفوظة النية النيار

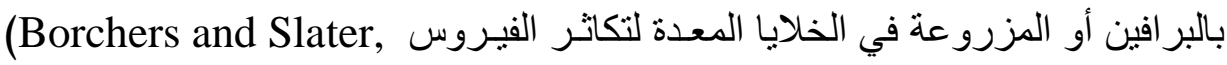
(Dutta et al., الكلاسيكية ELISA أما التشخيص المصلي بطريقة الإليزا (1993)

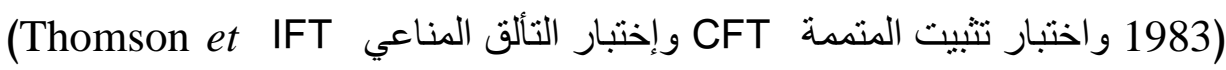

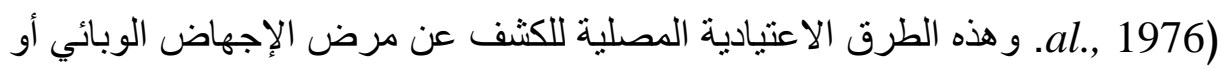
إلتهاب الأنف و الرئة الخيلي لا تفرق بين الإصابة بالنمط المصلي 1 و النمط المصلي 4

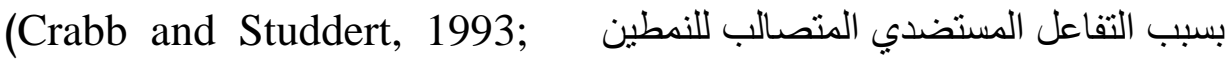
Crabb and Studdert 1995; Hartley et al., 2005) تطوير نوع خاص من الإليز التشخيص الإصابة بين النمطين 1 و و 4 بعتمد على تقنية جديدة تعتمد على اختلاف الجزء الطرفي (سي) البروتيني من البرونين البرني السكري (جي) لكلا النمطين ELISA based on the C-terminal portion of glycoprotein تعد الإليز ا المطورة طريقة يعتم د عليها ومفضلكة بسبب الفائدة التطبيقية له ذا الإختبلر وحساسيته بالمقارنة مع الاختبار ات المصلية الأخرى. (Crabb and Studdert, 1993; Crabb and Studdert et al., 1995; .Yasunaga et al., 2000; Hartley et al., 2005)

\section{OBJECTIVES}




\section{أهداف البحث}

1 - تحديد وجود الحالات الإيجابية مصليا ل لمرض الإجهاض الوبائي عند الخيول و المعروف عالميا بالقوباء الخيلي (EHV-1 و EHV-4) في سورية.

2- تحديد نسبة هذه الحالات الإيجابية لتحديد انتشار المرض مصليا في المناطق المدروسة.

\section{MATERIALS and METHODS مـواد وطرائى العمل}

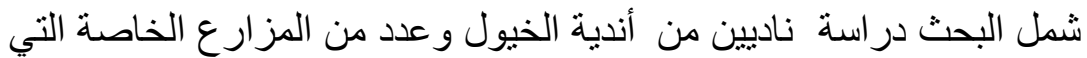

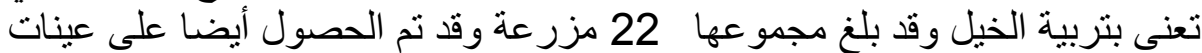

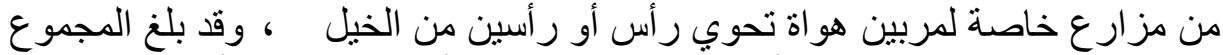

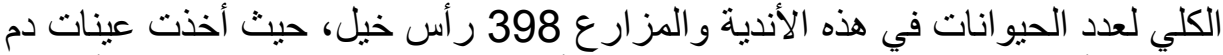

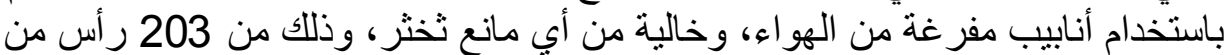

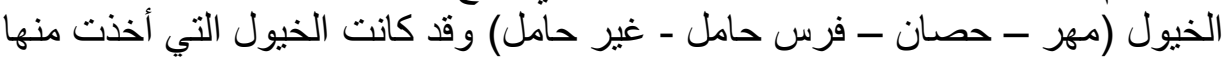

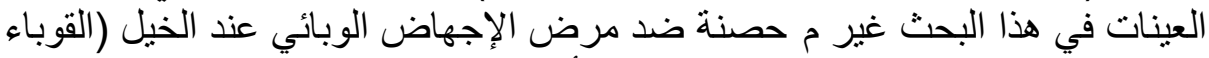

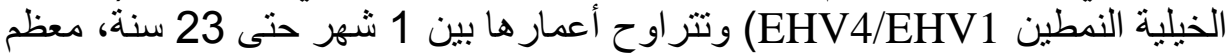

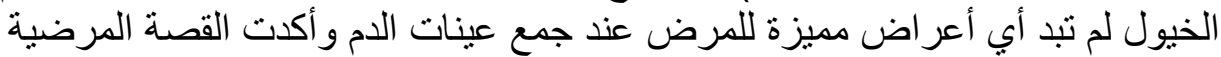

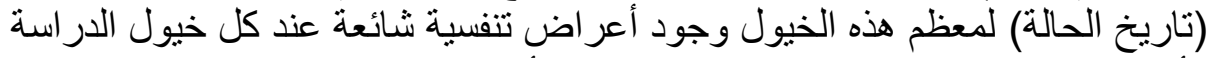

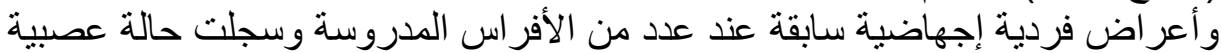

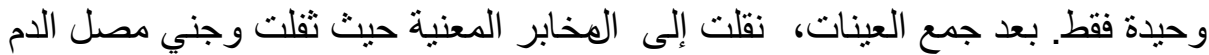
وأخضع لاختبار الأليزا الغير مباشرة. 
Assiut Vet. Med. J. Vol. 57 No. 130 July 2011

\begin{tabular}{|c|c|c|c|c|c|c|c|c|c|}
\hline & & & & & & & \multicolumn{3}{|c|}{ عينات المنطقة الجنوبية } \\
\hline رقم & الخيل & الجنس & العمر & ملاحظات & مكان جمع & EHV1 & النتيجة & $\begin{array}{c}\text { EHV } \\
4\end{array}$ & النتيجة \\
\hline 1 & مخفى & أنثى & 2.5 & & دمشق & 0.002 & - & 0.987 & + \\
\hline 2 & مخفى & أنثى & 6 & & دمشق & 0.136 & $-1+$ & 0.804 & + \\
\hline 3 & مخفى & أنثى & 3 & حامل & دمشق & 0.033 & - & 0.501 & + \\
\hline 4 & مخفى & أنثى & 5 & & دمشق & 0.089 & - & 0.861 & + \\
\hline 5 & مخفى & أنثى & 11 شهر & & دمشق & 0.001 & - & 0.368 & + \\
\hline 6 & مخفى & أنثى & 12 & حامل & دمشق & 0.015 & - & 0.829 & + \\
\hline 7 & مخفى & أنثى & 4 & حامل & دمشق & 0.039 & - & 2.271 & + \\
\hline 8 & مخفى & ذكر & 8 & & دمشق & 0.022 & - & 0.86 & + \\
\hline 9 & مخفى & أنثى & 23 & |جهاض 4 أثشر & دمشق & 0.002 & - & 0.46 & + \\
\hline 10 & مخفى & أنثى & 4 & والدة & دمشق & 0.039 & - & 0.759 & + \\
\hline 11 & مخفى & أنثى & 3 & & دمشق & 0.005 & - & 1.455 & + \\
\hline 12 & مخفى & ذكر & 2 & & دمشق & 0.037 & - & 1.157 & + \\
\hline 13 & مخفى & أنثى & 3.5 & & دمشق & 0.196 & $-1+$ & 1.78 & + \\
\hline 14 & مخفى & أنثى & 3 & & دمشق & 0.239 & + & 1.532 & + \\
\hline 15 & مخفى & أنثى & 4 & & دمشق & -0.019 & - & 1.245 & + \\
\hline 16 & مخفى & انثى(ابنة17) & 2 & & دمشق & 0.004 & - & 0.03 & - \\
\hline 17 & مخفى & أنثى & 5 & & دمشق & 0.054 & - & 1.272 & + \\
\hline 18 & مخفى & أنثى & 10 & حامل ع الولادة & دمشق & 0.022 & - & 1.299 & + \\
\hline 19 & مخفى & أنثى & 2.5 & التهاب صفائح & دمشق & -0.011 & - & 0.649 & + \\
\hline 20 & مخفى & أنثى & 3.5 & هولندى & دمشق & -0.017 & - & 1.37 & + \\
\hline 21 & مخفى & ذكر & 4 & بونى & دمثق & 0.019 & - & 1.929 & + \\
\hline 22 & مخفى & أنثى & 18 & التهاب رحمية & دمشق & -0.004 & - & 1.392 & + \\
\hline 23 & مخفى & أنثى & 7 & حامل 9 أثشهر & دمشق & 0.067 & - & 1.127 & + \\
\hline 24 & مخفى & ذكر & 16 & & دمشق & 0.015 & - & 1.471 & + \\
\hline 25 & مخفى & أنثى & 4 & حامل & دمشق & 0.017 & - & 0.432 & + \\
\hline 26 & مخفى & أنثى & 4 & حامل & دمشق & 0.111 & $-1+$ & 1.287 & + \\
\hline 27 & مخفى & أنثى & 7 & حامل & دمثق & 0.055 & - & 1.633 & + \\
\hline 28 & مخفى & ذكر & 6 & & دمشق & 0.041 & - & 1.508 & + \\
\hline
\end{tabular}

صورة لقاعدة البيانات التى جمعت أثثاء جمع العينات من المزارع المختلفة تبين نوع جنس ورقم العينة والملاحظات قبل عملية أخذ عينة الدم. 
اختبار المقايسة المناعية المرتبط بالإنزيم ELISA للكثف عن الإجهاض الوبائي

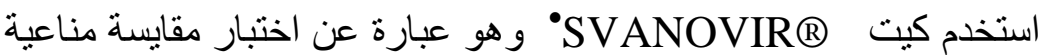

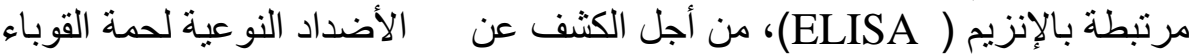

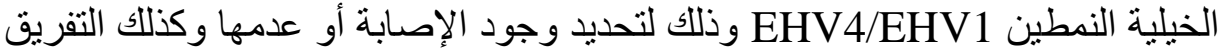

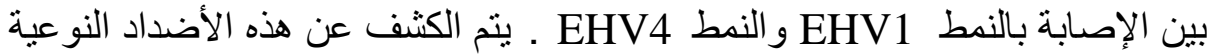
في المصل و البلازما عند الخيول.

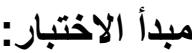

يتكون الكيت من أطباق خاصة باختبار الإليز اليهتوي كل منها على 96 حفرة،

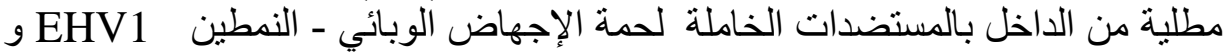
EHV4 حيث تتوزع الحفر في كل طبق على الثلى الشكل التالي:

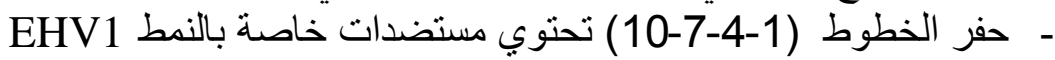

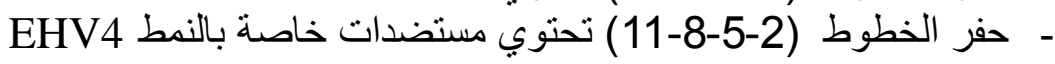

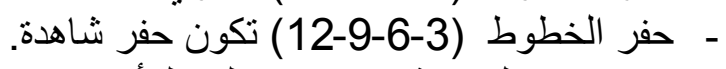

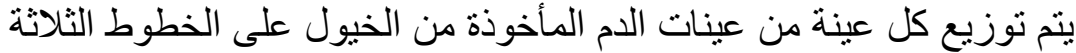

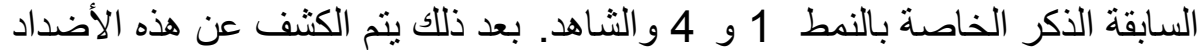

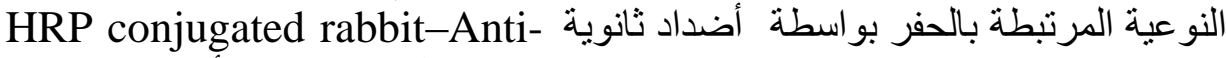
موسومة بالبيروكسيداز وجاهزة للاستعمال والتي تقوم بأكسدة الدارئة (IgG-horse) إلى

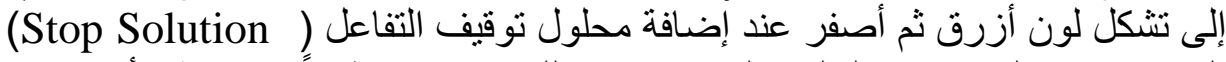

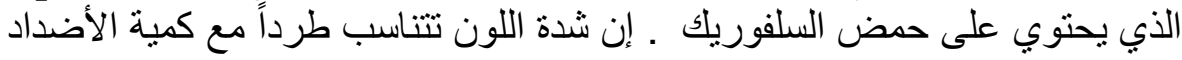

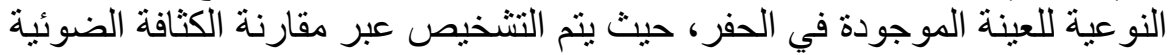

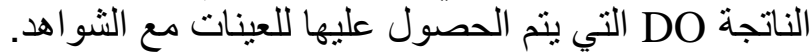

\section{طريقة العمل}

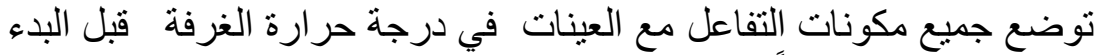

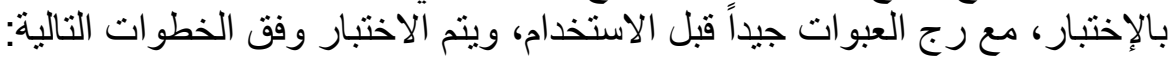

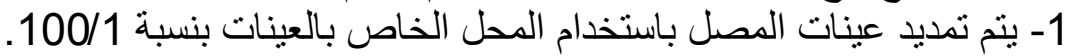

- SVANOVIR ${ }^{\circledR}$ - Equine Herpes Virus Type 1 and 4 Discriminating test (EHV1/EHV4-Ab)- SVANO 
2- نقوم بعد ذلك بتوزيع 100 ميكروليتر من كل عينة على 3 حفر من حفر الطبق: حفرة للكثف عن الأضداد النوعية للنمط 100 و وحفرة للكثف عن أضداد النمط 4 وحفرة شاهد مستضدي (Control antigen)

3- نقوم بإضافة 100 ميكروليتر من محلول الثناهد الإيجابي والسلبي في الحفر

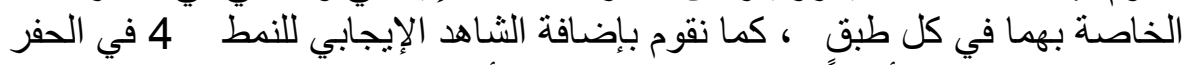

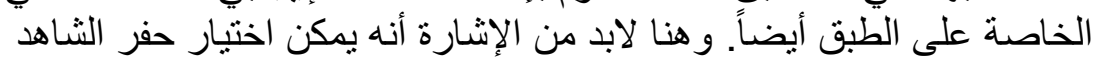

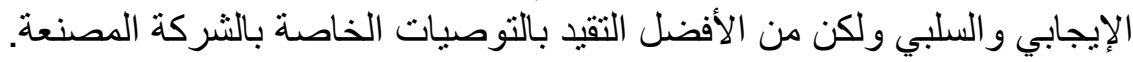

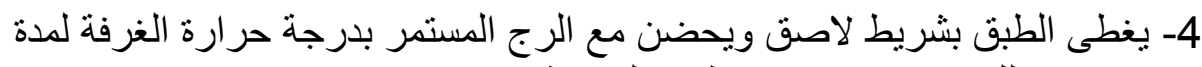
ساعتين وذللك باستخدام رجاج بطيء السرعة.

5- تغسل كل حفرة 4 مرات بواسطة 300 ميكروليتر من محلول الغسيل Tween buffer

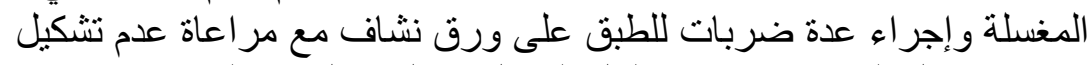
فقاعات داخل الحفر وإخر اج محلول الغسيل بشكل كامل من الحفر.

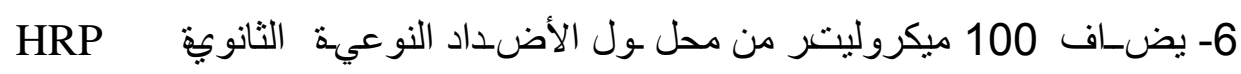
(الموسومة بالبيروكسيداز. 7- يحضن الطبق بدرجة حرارة الغرفة مع الرج المستمر لمدة ساعة واحدة. 8- تكرر المرحلة رقم /5/ من أجل الغسيل.

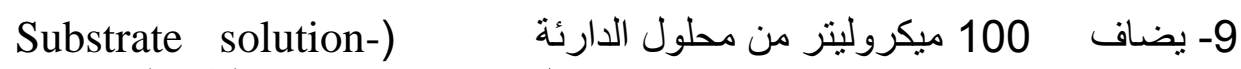
TetraMethyl-Benzidine, TMB دقائق بدرجة حرارة الغرفة. نبدأ بالتوقيت من لحظة ملئ أول حفرة من حفر الطب الطبق.

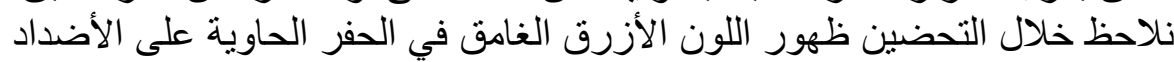

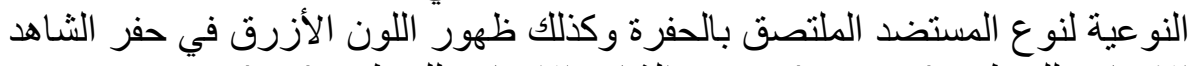

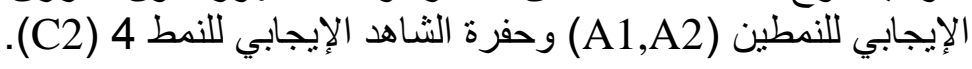

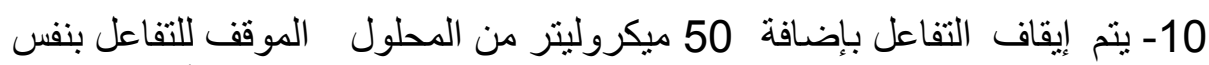

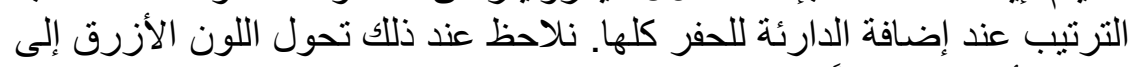
الألون الأصفر مباشرةً.

11- تقرأ النتيجة باستخدام مقياس الطيف الضوئي على موجة طولها 450 نانومتر. 


\section{بعد قراءة الجهاز للطبق نقوم بتصحيح أرقام القراءة للطبق باستخدام معادلة

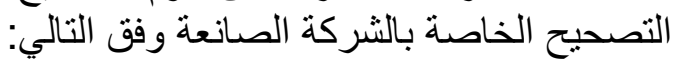

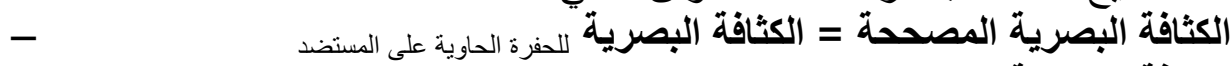 \\ OD Corr = OD Antigen - OD Control antigen}

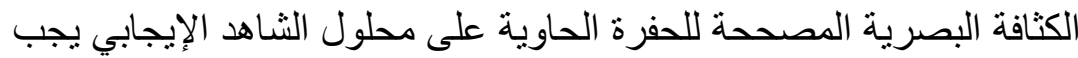

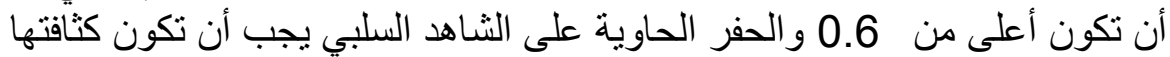
البصرية المصححة أعلى من 0.10.

\section{تفسير النتيجة:}

الكثافة البصرية > 0.2 : العينة المصلية إيجابية للحفرة.

الكثافة البصرية > 0.1 : العينة المصلية سلبية للحفرة.

الكثافة البصرية 0.1 - 0.2 : : العينة المصلية مشتبهة.

أما فيما يتعلق بالحساسية والنوعية لهذا الاختبار فقد درست من قبل

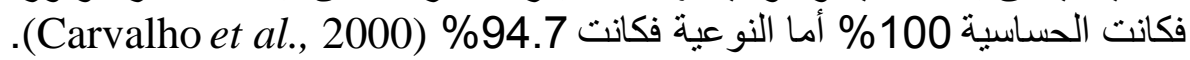

\section{RESULTS}

\section{النتائج}

أظهرت نتائج اختبار الإليز ا غير المباشرة (المقايسة المناعية الأنزيمية)

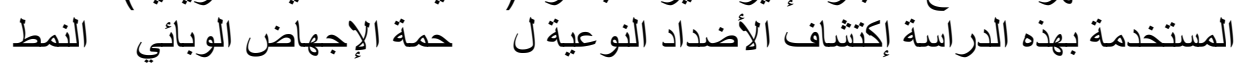

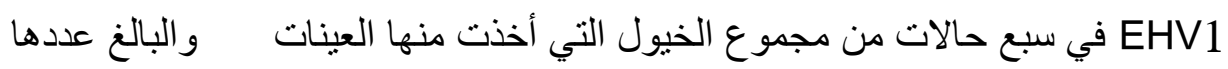

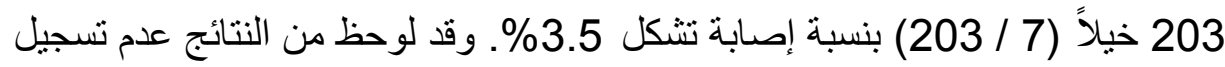

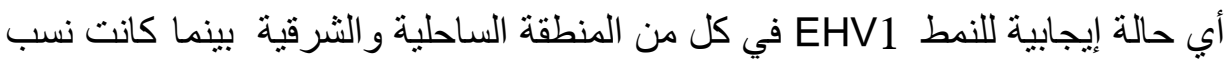

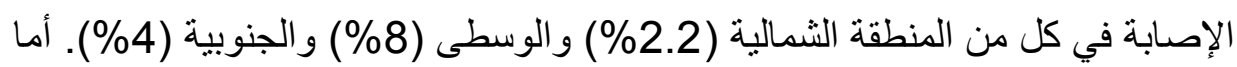

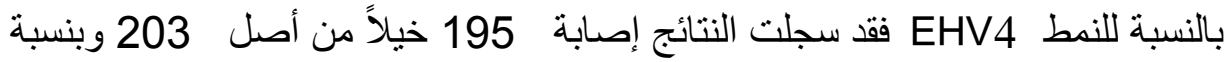

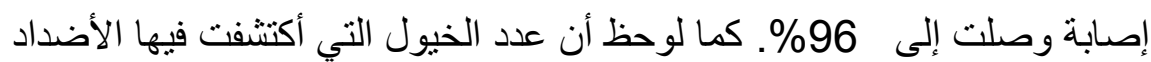
النو عية للنمطين هي ( 7) حالات فقط من مجموع الحالات المدروسة الحة في هذا البحث

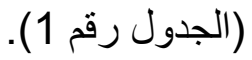

الجدول رقم 1: يبين توزع العينات الإيجابية مصلياً والنسب المئوية للإصابة لكلا

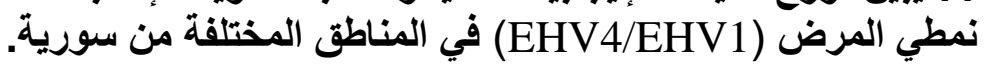


Assiut Vet. Med. J. Vol. 57 No. 130 July 2011

\begin{tabular}{|c|c|c|c|c|c|}
\hline \multicolumn{2}{|c|}{ النمط EHV4 } & \multicolumn{2}{|c|}{ النمط EHV1 } & \multirow[b]{2}{*}{ العينات } & \multirow[b]{2}{*}{ اسم المنطقة } \\
\hline الإصابة & الإلعينات & الإصابة & الإلعينات & & \\
\hline 98 & 49 & 4 & 2 & 50 & المنطقة الجنوبية \\
\hline 90 & 47 & 8 & 4 & 50 & المنطقة الوسطى \\
\hline 93,3 & 42 & 2,2 & 1 & 45 & المنطقة الثمالية \\
\hline 97,5 & 39 & 0 & 0 & 40 & المنطقة الثرقية \\
\hline 100 & 18 & 0 & 0 & 18 & المنطقة الساحلية \\
\hline 96 & 195 & 3,5 & 7 & 203 & المجموع الكلي \\
\hline
\end{tabular}

\section{للنمطين الإيجابية العينات توزع}

\section{E HV4/E HV1}

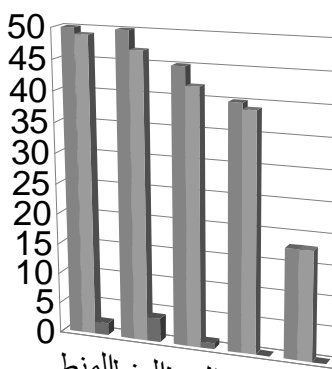

$$
\begin{aligned}
& \text { المنط المنط المنطالمنطالمنط } \\
& \text { قة قة قة قة قة قلة قلة } \\
& \text { السا الثر الثمالوسلة لئهن } \\
& \text { حلية قية لية طى بية }
\end{aligned}
$$

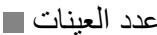

العينات الإيجابية للنمط 4

العينات الإيجابية للنمط 1 |

المنطقة المنطقة المنطقة المنطقة المنطقة

الساحلية الشرقية الثمالية الوسطى الجنطية النطوبية

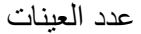

\begin{tabular}{|l|l|l|l|l|}
\hline 50 & 50 & 45 & 40 & 18 \\
\hline 49 & 47 & 42 & 39 & 18 \\
\hline
\end{tabular}

التحليل الإحصائي للنتائج : 
The استخدمنا في التحلي لـ الإحص -ائي له ذا المس-ح توزيع المعاينة للنسبة :Sampling Distribution of the Proportion

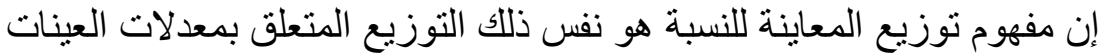

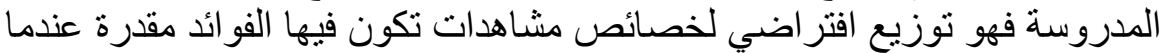

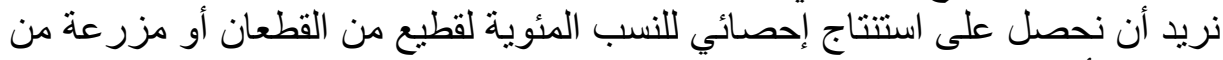

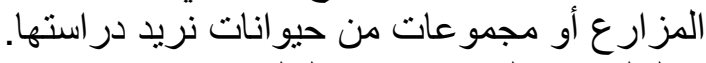
وبالتالي فإن النتائج تكون كالتالي :

$$
\left(\mathrm{SE}_{\mathrm{p} 1}=0.14\right) \text { (0.013-0.07, CI 95\%) }
$$

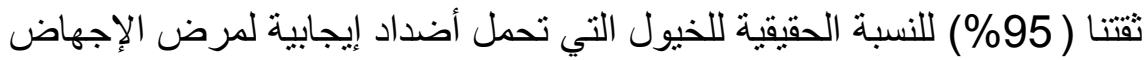
الوبائي عند الخيل (القوباء الخيلية النمط $\left(\mathrm{SE}_{\mathrm{P} 4}=0.014\right)$ (0.93-0.98 , CI 95\%)

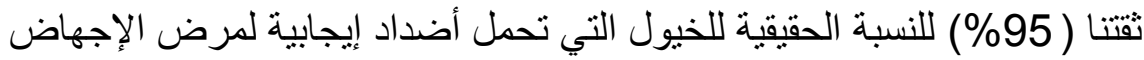

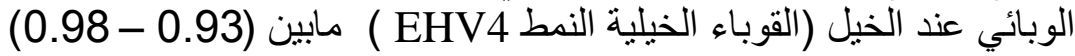

E HV11 بالنمط للإصابة المئوية النسبة

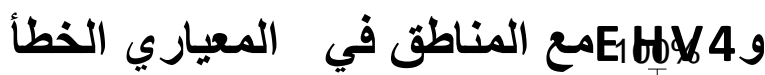
$98 \%$ 


\section{DISCUSSION}

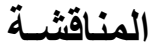

إن الغاية من هذه الدراسة هي الكثف عن الأضد الخداد الخاصة بالحمة المسيبة

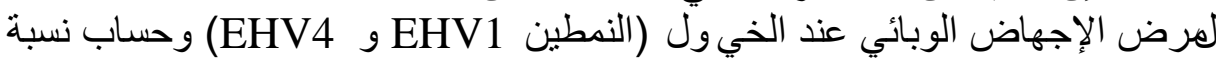

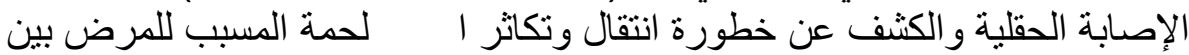
المناطق المدروسة.

فقد أكد الباحثون على أهمية هذا المرض من حيث كمون الإصابة و وعودتها

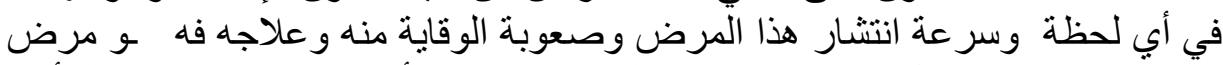

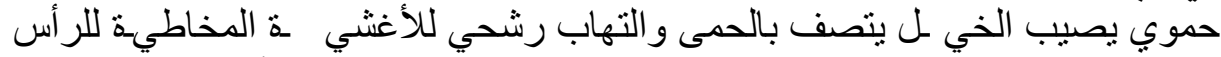

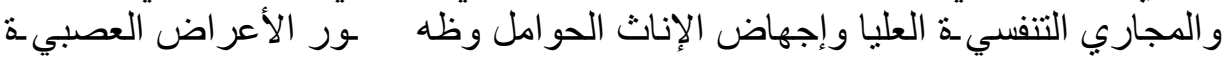

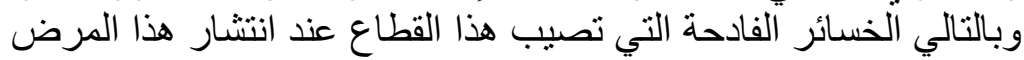
(O’Callaghan et al., 1983 ; Allen and Bryans, 1986 ; Bryans and Allen, 1988 ; Matsumura et al., 1992 ; Crabb and Studdert, 1995 ; Allen et al., 1999) فقد أثثت وجود المرض في مناطق عديدة من العالم و التي تهتم بتربية الخيول

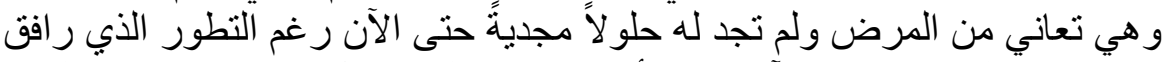

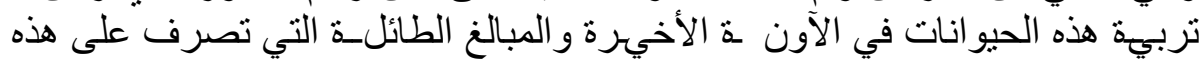

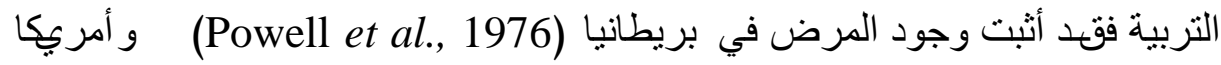
(Carman et وكندا Doll and Bryans, 1963; Mumford et al.,1998) (Bagust and Pascoe, 1968 ; $\quad$ Duxbury and Oxer, وأستر اليا al., 1997) 1968 ; Studdert et al., 1974 ;

Crabb and Studdert, 1995; Gilkerson et al., 1997 ; Gilkerson et al., 1999)

ونيوزيلندا (Jolly et al., 1986) و اليابان (Kawakami et al., 1962) وتركيا Ataseven(Gür,s and Yapici., 2008; et al., 2009) و الإمارات (OIE,2010) وجنوب إفريقيا (Mason et al., 1989).

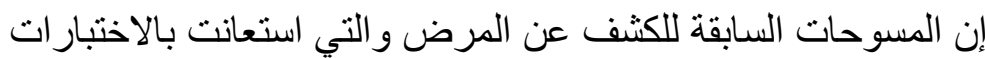

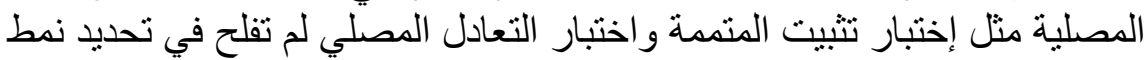

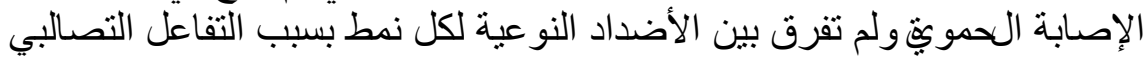

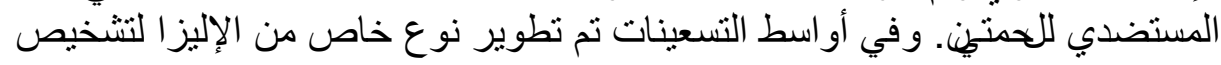

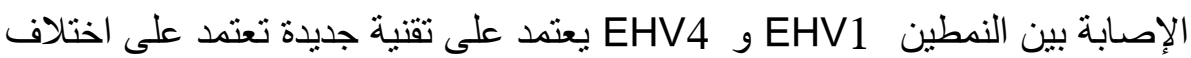

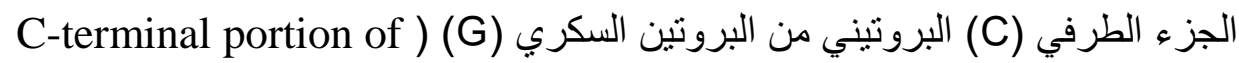


(glycoprotein G

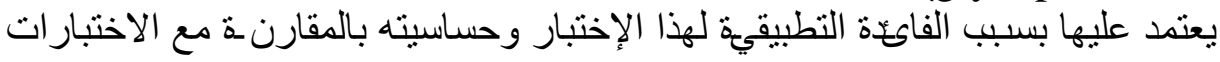

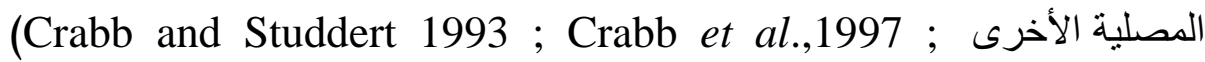

.Yasunaga et al., 2000 ; Hartley et al., 2005) كما أكد et al., 2000) (Van Maanen أن الإليز ا أكثر حساسية من اختبار

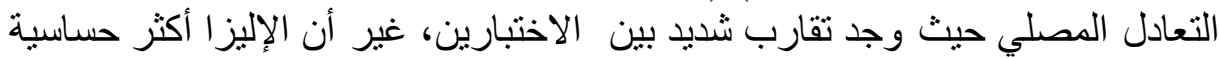

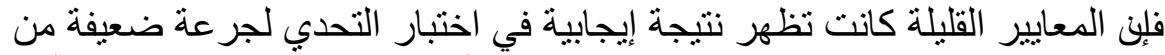

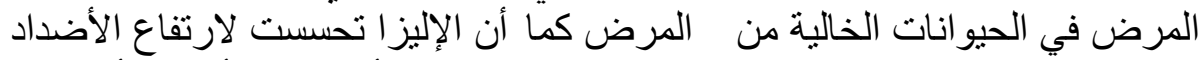

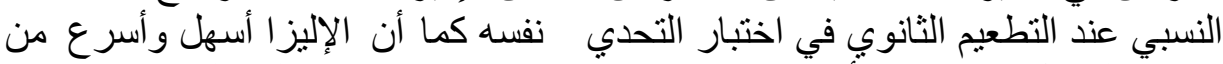

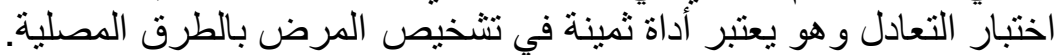

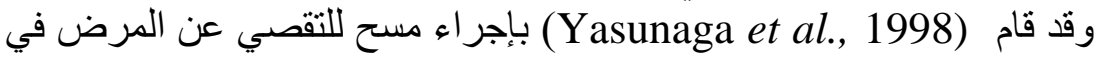

اليابان بإستخدام طريقة الإليز ا غير المباشرة المطورة التي تعتمد على الغليكوبروتين (glycoprotein Gs (gGs)) التفريق بين الإصابتين وهذه التقنية هي نفس التقنية التي استخدمت في هذا البحث و وهي

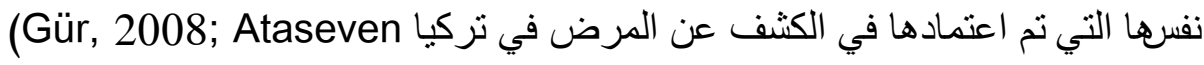
.et al., 2009)

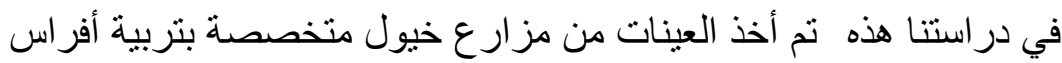

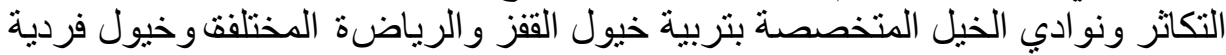

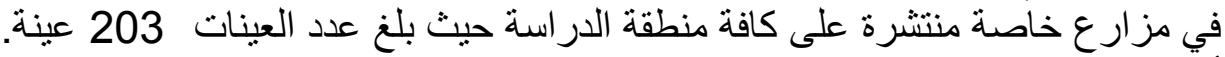

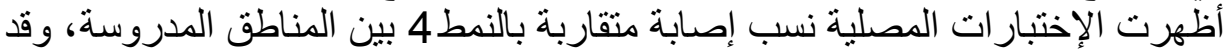

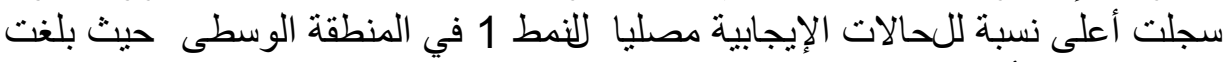

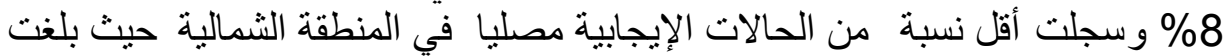

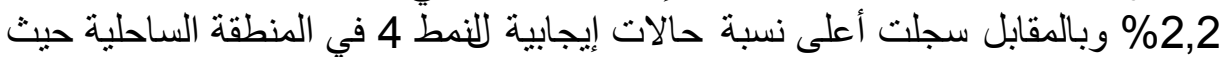
بلغت 100\%.

لقد كانت نتائج الإختبار مماثلة لتلك التي سجلت في الأبحاث التي جرت مسبقاً

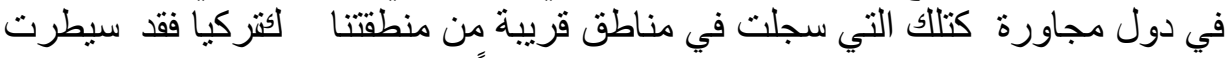

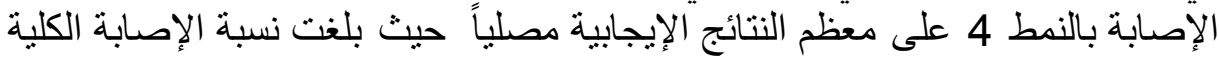

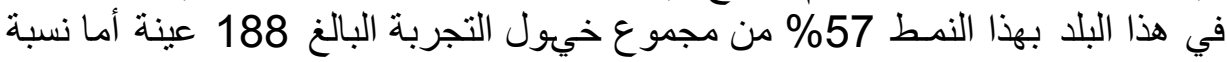
الإصابة بالنمط 1 فقد بلغت 3,7\% من مجموع 188 عينة (Gür, 2008).

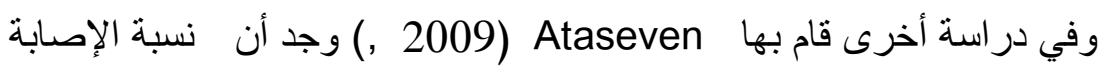

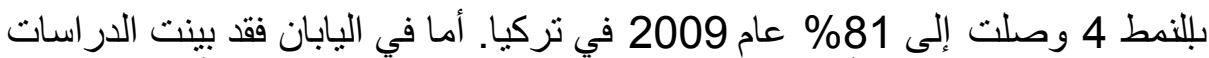

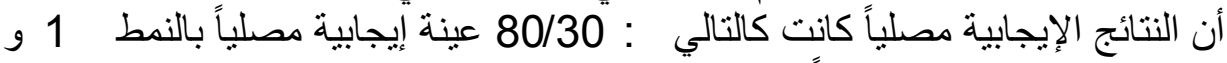

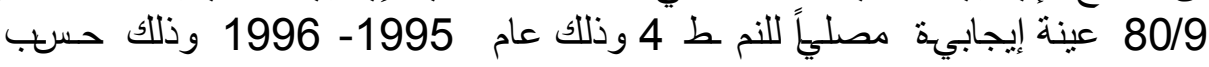
(Yasunaga, 1988) 
وحسب تقارير مكتب الأوبئة الدولي للعينات الواردة إلى المخابر كانت النتائج

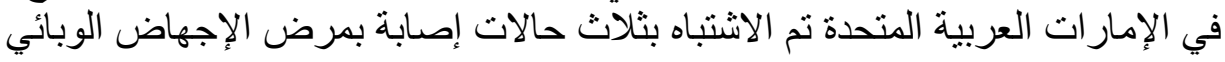

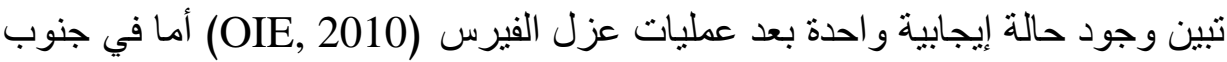

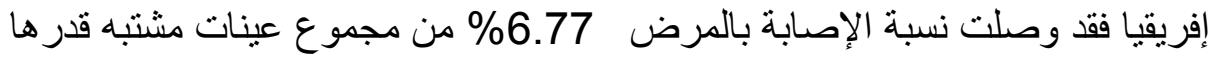

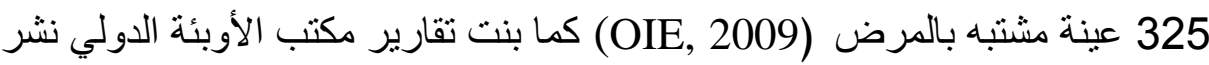

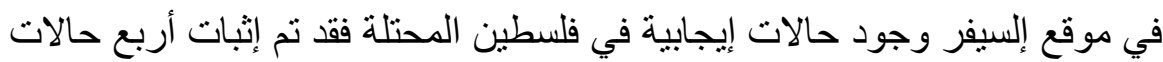

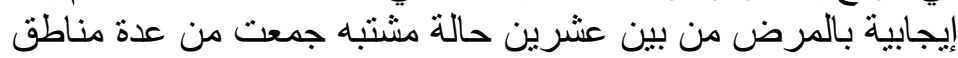

(Crabb et كما أكد كراب ورفاة اطنه (intl.elsevierhealth.com/journals/trst)

al., 1997) الخيلية النمطين المصليين 4/1 كانت كل العينات إيجابية للنمط المصلي يتو افق مع النتائج التي حصلنا عليها في هذه الدراسة.

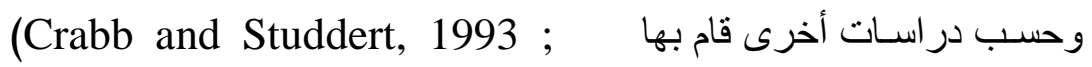

Gilkerson et al., 1994 ; Van Maanen et al., 2000)

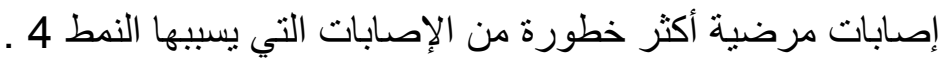

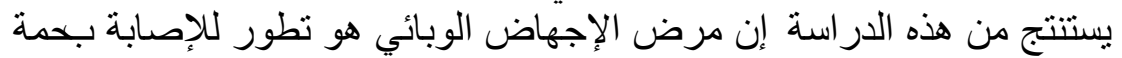

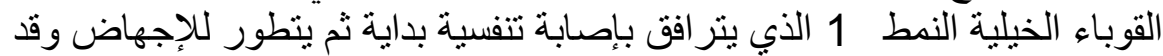

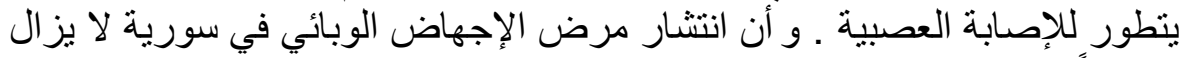

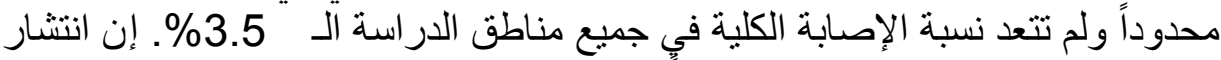

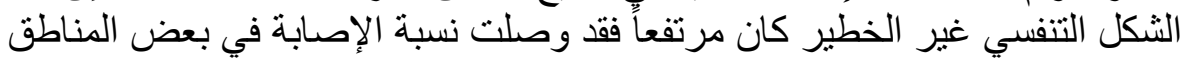

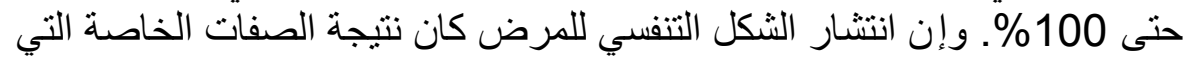

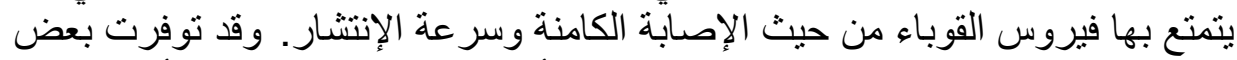

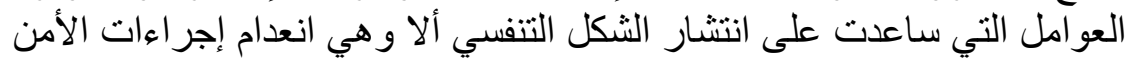

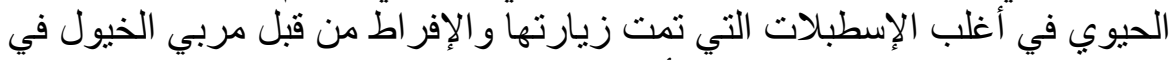

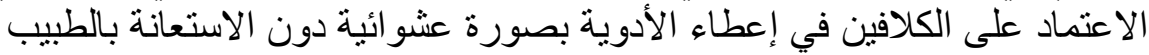

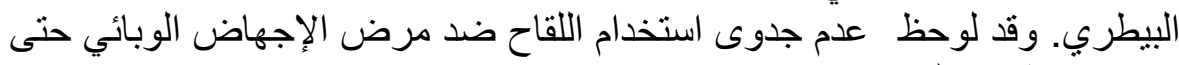
تاريخ كتابة هذا البحث.

\section{REFERENCES}

Allwn, G.P.; Kydd, J.H.; Slater, J.D. and Smith, K.C. (1999): Recent advances in understanding the pathogenesis, epidemiology, and immunological control of equid 
herpesvirus-1 (EHV-1) abortion. Equine Infect. Dis., 8: 129-146.

Allen, G.P.; Kydd, J.H. and Slater, J.D. (2004): Equid herpesvirus 1 and equid herpesvirus 4 infections. In: Coetzer JAW, Tustin RC, eds. Infectious Diseases of Livestock, $1^{\text {st }}$ ed. Newmarket: Oxford University Press., 829-859.

Allen, G.P. and Bryans, J.T. (1986): Molecular epizootiology, pathogenesis, and prophylaxis of equine herpesvirus-1 infection. in Veterinary Microbiology and Immunology, 2: 78-144.

Ataseven, V.S.; Dagalp, S.B.; Güzelm, Basaran, Z.; Tan, M.T. and Geraghty, B. (2009): Prevalence of equine herpesvirus-1 and equine herpesvirus-4 infections in equidae species in Turkey as determined by ELISA and multiplex nested PCR. Res. Vet. Sci., 86(2): 339-44.

Bagust, T.J. and Pascoe, R.R. (1968): Isolation of equine rhinopneumonitis virus from acute respiratory disease in a horse in Queensland.Aust. Vet. J., 44: 296.

Ballagi, A.; Klingeborn, B.; Flensburg, J. and Belak, S. (1990): Equine herpesvirus type 1: detection of viral DNA sequences in aborted fetuses with the polymerase chain reaction. Vet. Microbiol., 22: 373-381.

Betteridge, K.J. (1989): The structure and function of equine capsule in relation to embryo manipulation and transfer. Equine Vet. J., 8: 92-100.

Borchers, K. and Slater, J. (1993): A nested PCR for the detection and differentiation of EHV-1 and EHV-4. J. Virol. Methods, 45: 331-336.

Bryans, J.T. and Allen, G.P. (1988): Herpesviral diseases of the horse. In: Herpesvirus Diseases of Animals,Wittman G., ed. Kluwer, Boston, USA, 176-229.

Bryans, J.T. and Allen, G.P. (1989): Herpesviral diseases of the horse. In: Herpesvirus Diseases of Cattle, Horses and Pigs, Ed: G. Wittmann, Kluwer, Boston, pp. 176-229.

Bryans, J.T. (1981): Application of management procedures and prophylactic immunization to the control of equine 
rhinopneumonitis. In: Proc. Am. Ass. Equine Practnrs, Anaheim, pp. 259-272.

Carman, S.; Rosendal, S.; Huber, L.; Gyles, C.; Mckee, S.; Willoughby, R.A.; Dubovi, E.; Thorsen, J. and Lein, D. (1997): Infectious agents in acute respiratory disease in horses in Ontario. J. Vet. Diagn. Invest., 9: 17-23.

Carter, G.R. and Wise, D.J. (2006): A Concise Review of Veterinary Virology, International Veterinary Information Service, Ithaca NY (www.ivis.org), Last updated: 9-May2006; A3411.0506.

Carvalho, R.; Passos, LMF.; Gouvea, A.M.G.; Resende, M.; Martins, A.S. and Franco, G.C. (2000): Use of an ELISA system for detection of equine herpesvirus 1 (EHV-1) antibodies in non-symptomatic pregnant mares and neonatal foals. Arq. Bras. Med. Vet. Zootec., 52, 3.

Carvalho, R.; Passos, LMF.; Oliveira, AM.; Henry, M. and Martins, A.S. (2000): Detection of equine herpesvirus 1 DNA in a single embryo and in horse semen by polymerase chain reaction. Arq. Bras. Med. Vet. Zootec., 4-52.

Crabb, B.S. and Studdert, M.J. (1995): Equine herpesviruses 4 (equine rhinopneumonitis virus) and 1 (equine abortion virus). Adv. Virus Res., 45: 153-190.

Crabb, B.S. and Studdert, M.J. (1993): Epitopes of glycoprotein G of equine herpesviruses 4 and 1 located near the c-termini elicit type-specific antibody responses in the natural host. J. Virol., 67: 6332-6338.

Crabb, B.S. and Studdert, M.J. (1994): Equine herpesviruses 4 (equine rhinopneumonitis virus) and 1 (equine abortion virus). Adv. Virus Res., 45: 153-190.

Crabb, B.S.; Macpherson, C.M.; Reubel, G.H.; Browning, G.F.; Studdert, M.J. and Drummer, H.E. (1997): Archives of Virology, 140(2): 245-258.

Doll, E.R. and Bryans, J.T. (1963): A planned infection program for immunizing mares against viral rhinopneumonitis. Cornell. Vet., 53: 249-262.

Dutta, S.K.; Talbot, N.C. and Myrup, A.C. (1983): Detection of equine herpesvirus-1 antigen and the specific antibody by 
enzyme-linked immunosorbent assay. Am. J. Vet. Res., 44: $1930-1934$.

Duxbury, AE. and Oxer, D.T. (1968): Isolation of equine rhinopneumonitis virus from an epidemic of acute respiratory disease in horses. Aust. Vet. J., 44: 58-63.

Edington, N.; Smith, B. and Griffiths, L. (1991): The role of endothelial cell infection in the endometrium, placenta and fetus of equid herpesvirus 1 (EHV-1) abortions. J. Comp. Pathol., 104: 379-387.

Edington, N.; Welch, H.M. and Griffiths, L. (1994): The prevalence of latent equid herpesviruses in the tissues of abattoir horses. Equine Vet. J., 26: 140-142.

Gilkerson, J.R.; Jorm, L.R.; Love, D.N.; Lawrence, G.L. and Whalley, J.M. (1994): Epidemiologic investigation of equid herpesvirus 4 (EHV 4) excretion assessed by nasal swabs taken from Thoroughbred foals. Vet. Microbiol., 39: 275-283.

Gilkerson, J.R.; Love, D.N. and Whalley, J.M. (1997): Serological evidence of equine herpesvirus 1 (EHV-1) infection in Thoroughbred foals 30-120 days of age. Aust. Equine Vet., 15: $128-134$.

Gilkerson, J.R.; Teague, N.; Whalley, J.M. and Love, D.N (1999): Aprospective cohort study of upper respiratory tract disease in one and two-year old racehorses. Serological evaluation of the roleof equine herpesviruses 1 and 4 (EHV-1 and EHV-4) in respiratory disease. Aust. Equine Vet. J. 17: 76-81.

$G \ddot{U} r$, S. and Yapici, O. (2008): Equine herpesvirus type 1 and 4 in individually reared horses in central and western Turkey. Acta Vet. Brno., 77: 609-613.

Hartley, C.A.; Wilks, C.R.; Studdert, M.J. and Gilkersony, J.R. (2005). Comparison of antibody detection assays for the diagnosis of equine herpesvirus 1 and 4 infections in horses. Am. J. Vet. Res., 66: 921-928.

Jolly, P.D.; FU, Z.F. and Rorbinson, A.J. (1986): Viruses associated with respiratory disease of horses in New Zealand: an update. N. Z.Vet. J., 34: 46-50. 
Kawakami, Y.; Kaji, T.; Ishizaki, R.; Shimizu, T. and Matumoto, M. (1962): Etiologic study on an outbreak of acute respiratory disease among colts due to equine rhinopneumonitis virus. Jpn. J. Exp.Med., 32: 211-229

Mason, D.K.; Watkins, K.L. and Luk, C.M. (1989): Haematological changes in two Thoroughbred horses in training with confirmedequine herpesvirus 1 infections. Vet. Rec., 124: 503-504.

Matsumura, T.; Sugiura, T.; Imagawa, H.; Fujanaga, Y. and Kamada, M. (1992): Epizootiological aspects of type 1 and type 4 equine herpesvirus infections among horse populations. J. Vet. Med. Sci., 54(2): 207-211.

Matumoto, M.; Ishizaki, R. and Shimizu, T. (1965): Serological survey of equine rhinopneumonitis virus infection among horses in various countries. Arch. Ges. Virusforsch., 50: 609-623.

Mumford, J.A.; Traub Dargatz, J.L.; Salman, M.D.; Collins, J.K.; Getzy, D.M. and Carman, J. (1998): Monitoring and detection of acute viral respiratory tract disease in horses. J. Am. Vet. Med. Assoc., 213: 385-390.

O'callaghan, D.J.; Gentry, G.A. and Randall, C.C. (1983): The equine herpesviruses. In: Roizman $\mathrm{B}$, editor. The Herpesviruses. New York: Plenum Press., p. 215-318.

OIE Terrestrial Manual, (2008): Chapter 2.5.9. - Equine rhinopneumonitis 849, 903.

OIE, WWW.oie.int, Information received on (2009): from $\mathrm{Mr}$ Bothle Michael Modisane, Chief Director Food and Veterinary Services, Department of Agriculture, Food Safety and Biosecurity: Department of Agriculture, PRETORIA, South Africa.

OIE, WWW.oie.int, Information received on (2010): from Eng Sumaia Al Rais, Head of Animal and Plant Health, Animal and Plant Health Department, Ministry of Environment and Water, Dubai, United Arab Emirates.

Patel, J.R. and Heldens, J. (2005): Equine herpesviruses 1 (EHV1) and 4 (EHV-4) - epidemiology, disease and 
immunoprophylaxis: a brief review. The Veterinary Journal, 170: 14-23.

Powell, D.G.; Burrows, R.; Spooner, P.R.; Goodridge, D.; Thomson, G.R. and Mumford, J. (1976): A study of infectious respiratory disease among horses in Great Britain, 1971 to 1976. In: Bryans, J., Gerber, H. (Eds.), Proceedings of the Fourth International Conference on Equine Infectious Diseases, Veterinary Publications, New Jersey, pp. 451-459.

Reed, S.M. and Toribio, R.T. (2004): Equine herpesvirus 1 and 4. Veterinary Clinics of North America Equine Practice, 20: 631-642.

Sabine, M.; Robertson, G.R. and Whalley, J.M. (1981):

Differentiation of sub-types of equine herpesvirus 1 by restriction endonuclease analysis. Aust. Vet. J., 57: 148-149. Slater, J. (2007): Equine herpesviruses. In: Sellon, D., Long, M. (Eds.), Equine Infectious Diseases. Saunders Elsevier, St. Louis, USA, pp. 134-153.

Studdert, M.J. (1974): Comparative aspects of equine herpesviruses. Cornell. Vet., 64: 94-122.

Telford, E.A.R.; Watson, M.S.; Mcbride, K. and Davison, A.J. (1992): The DNA sequence of equine herpesvirus-1. Virology, 189: 304-316.

Telford, E.A.R.; Watson, M.S.; Perry, J.; Cullinane, A.A. and Davison, A.J. (1998): The DNA sequence of equine herpesvirus 4. J. Gen. Virol., 79: 1197-1203.

Thomson, G.R.; Mumford, J.A.; Campbell, J.; Griffiths, L. and Clapham, P. (1976): Serological detection of equid herpesvirus 1 infections of the respiratory tract. Equine Vet. J., 8: 58-65.

Van Maanen, C. (2002): Equine herpesvirus 1 and 4 infections: an update. Veterinary Quarterly, 24: 58-78.

Van Maanen, C.; Vreeswijk, J.; Moonen, P.; Brinkhof, J.; De Boer-Luijtze, E. and Terpstra, C. (2000): Differentiation and genomic and antigenic variation among fetal, respiratory and neurological isolates from EHV 1 and EHV 4 infections in the Netherlands. Vet. Q., 22: 88-93. 
Welch, H.M.; Bridges, C.G.; Lyon, A.M.; Griffiths, L. and Edington, N. (1992): Latent equid herpesviruses 1and 4: detection and distinction using the polymerase chain reaction and co-cultivation from lymphoid tissues. J. Gen. Virol., 73: 261-268.

Yasunaga, S.; Maeda, K.; Matsumara, T.; Kondo, T. and Kai, K. (2000): Application of a type spesific enzymelinked immunosorbent assay for equine herpesvirus types 1 and 4 (EHV-1 and -4) to horse populations inoculated with inactivated EHV-1 vaccine. J. Vet. Med. Sci., 62: 687-691.

Yasunaga, S.; Maeda, K.; Matsumara, T.; Kai, K.; Iwata, H. and Inoue, T. (1998): Department of Veterinary Microbiology, Faculty of Agriculture, Yamaguchi University, Japan. Diagnosis and sero-epizootiology of equine herpesvirus type 1 and type 4 infections in Japan using a type-specific ELISA. J. Vet. Med. Sci., 60(10): 1133-1137. 